\title{
Processamento cognitivo relacionado à produção em língua estrangeira e aprendizagem de falantes não-nativos de alemão
}

\author{
Kelly Stanich \\ Selma Meireles*
}

\begin{abstract}
Cognition can be defined as a process of knowledge acquisition that draws upon environmental information as well as on material registered in our memory. This process, which is not always conscious, involves perception, attention, memory and action. It is therefore not only merely acquisition of knowledge, but also a process of converting all that is apprehended by the learner in accordance with his identity and experiences. This work proposes a theoretical model for cognitive processes related to foreign language production, relying on recent neuroscientific theories about memory, learning and processing of representations of frequent linguistic sequences (chunks), focusing on data concerning German as a foreign language. As a result, theoretical knowledge about a foreign language and the abilities to use it are seen as complementing skills that interact during the learning process, rather than different stages of the same knowledge defined by time of learning and storage in the memory, as suggested by some authors.
\end{abstract}

Keywords: memory and language; cognition and language; chunks; foreign language production; knowledge automatization.

Resumo: A cognição pode ser definida como um processo de aquisição de conhecimento que tem como material a informação do meio em que vivemos e o que já está registrado na nossa memória. Este processo envolve percepção, atenção, memória e ação, e nem sempre acontece de forma consciente. Mais do que simplesmente a aquisição de conhecimento, é um processo de conversão de tudo o que é captado pelo aprendiz de acordo com sua identidade e suas experiências. Com base nesse conceito, propõe-se um modelo teórico para o processamento cognitivo relacionado à produção em língua estrangeira, fundamentado em teorias recentes da neurociência sobre memória, aprendizagem e processamento de representações de sequiências freqüentes na língua (chunks) e ilustrado com dados referentes ao alemão como língua estrangeira. Como resultado, nota-se que o conhecimento teórico sobre a língua estrangeira e a capacidade de utilizá-la são habilidades complementares que interagem na aprendizagem da mesma, mas como saberes distintos, e não estágios do mesmo conhecimento determinados pelo tempo de aprendizagem ou armazenamento na memória, como sugerem alguns teóricos da área.

\footnotetext{
Kelly Stanich (kellystanich@gmail.com):Doutora em língua alemã pela Faculdade de Filosofia, Letras e Ciências Humanas da USP (FFLCH-USP); Selma Meireles (selmamm@usp.br): Professora-doutora do Departamento de Letras Modernas da FFLCH-USP.
} 


\section{Stanich, K.; Meireles, S. - Processamento cognitivo}

Palavras-chave: memória e linguagem; cognição e linguagem; chunks; produção em língua estrangeira; automatização do conhecimento.

Zusammenfassung: Aus der Sicht der Neurowissenschaft kann Kognition als ein WissenserwerbProzess definiert werden, der sowohl Informationen aus der Umwelt als auch aus unserem Gedächtnis verwendet. Der Prozess baut auf Perzeption, Aufmerksamkeit, Gedächtnis und Handeln auf und läuft nicht immer bewusst ab. Es handelt sich dabei aber nicht nur um Wissenserwerb, sondern um die Umwandlung all dessen, was vom Lerner anhand seiner Identität und Erfahrungen wahrgenommen wird. Davon ausgehend wird hier ein theoretisches Modell der Wissensverarbeitung im Rahmen der Produktion in einer Fremdsprache vorgestellt, das auf neuen neurowissenschaftlichen Theorien über Gedächtnis, Lernen und die Verarbeitung von Repräsentationen häufiger linguistischer Sequenzen (chunks) basiert und mit Daten aus dem Bereich Deutsch als Fremdsprache illustriert wird. Aus dem Modell ergibt sich, dass theoretisches Wissen über eine Fremdsprache und die Fähigkeit, die Sprache erfolgreich zu verwenden, als einander ergänzende, während des Lernprozesses miteinander interagierende Fähigkeiten anzusehen sind, und nicht als zwei Phasen einer durch Lernzeit und Speicherung im Gedächtnis bestimmten einheitlichen Kenntnis, wie von manchen Autoren vorgeschlagen wird.

Stichwörter: Sprache und Gedächtnis; Sprache und Kognition; chunks; Fremdsprachenproduktion; Wissensautomatisierung.

\section{Introdução}

KRASHEN (1982: 10s.), em sua hipótese sobre a distinção entre aquisição e aprendizagem, define a aquisição como um processo involuntário de internalização "natural" da linguagem, com foco no significado e que não requer conhecimento consciente das regras gramaticais correspondentes. A aprendizagem, por sua vez, é vista como um processo consciente, que envolve a capacidade de reconhecer e explicar essas regras e ocorre geralmente em situação formal de ensino (idem). Entretanto, o autor afirma que, embora a aquisição seja típica das crianças (já que essas, em situações normais, adquirem inevitavelmente a língua), os adultos podem servir-se dos dois processos: podem aprender e também adquirir a língua, pelo menos em alguma medida. Segundo GONZÁLEZ (1994), a aquisição pode ser compreendida como "saber usar a língua" e a aprendizagem, como "saber sobre a língua",

\footnotetext{
${ }^{1}$ É interessante notar que a lingua alemã faz distininăo entre o "saber teórico" (wissen) e as capacidades/habilidades (können), por ex.: Ich weiß, was du meinst (Sei o que você quer dizer) / Ich kann Klavier spielen (Sei tocar piano) O mesmo acon tece no inglês: I know what you mean, mas: I can play the piano.
} 


\section{Stanich, K.; Meireles, S. - Processamento cognitivo}

Como complemento à hipótese da distinção entre aquisição e aprendizagem, KRASHEN propõe hipóteses sobre o monitor, sobre uma ordem natural de aprendizagem, sobre input, intake e sobre um filtro afetivo. As principais críticas às suas hipóteses fundamentam-se no fato de o autor ter apresentado, nas primeiras versões de seu trabalho, os processos de aquisição e aprendizagem como sendo independentes. Outra fonte de críticas advém das dificuldades de comprovação empírica dos mecanismos responsáveis pelos dois tipos de processos. Contudo, embora dê apenas os primeiros passos na direção de uma distinção entre processos envolvidos na aprendizagem, o trabalho de Krashen aponta, como nenhum outro, para um caminho interessante a ser seguido, se quisermos explicar uma das questões mais curiosas que podemos observar em nossas experiências com o ensino/aprendizagem de língua estrangeira (LE): as diferenças entre o conhecimento consciente sobre a língua e suas regras e a habilidade de uso da língua na comunicação.

As pesquisas em aquisição da linguagem apontam cada vez mais para a interação de múltiplos fatores que interferem no processo de aprendizagem de uma língua ${ }^{2}$. Diversos autores (como KRASHEN (1977, 1982, 1985), MCLAUGHLIN (1978), BIALYSTOK (1978), SinCLAIR (1991) e KLEIN (1992), entre outros) referem-se a duas formas de aquisição ou de processamento do conhecimento linguístico, uma que estaria mais relacionada à aprendizagem e utilização de regras explícitas e outra relacionada à aprendizagem e utilização mais automatizada da língua. MCLAUGHLIN e BIALYSTOK propõem a automatização do conhecimento pela passagem de um sistema de armazenamento para outro. Para MCLAUGHLin (1978), através da prática, processos controlados se convertem em processos automáticos, à medida que são armazenados na memória de longa duração. Essa proposta fundamenta-se no modelo de memória proposto na década de 60 por ATKINSON e SHIFFRIN (1968). No entanto, a idéia de que a memória como um todo ou qualquer um de seus subsistemas privilegie o decorrer do tempo como fator determinante na manutenção, transferência ou descarte de seus conteúdos é controversa. Além disso, até o momento, não há consenso sobre o limite temporal que determinaria a passagem da informação do sistema de curta para o de longa duração. Trabalhos nas áreas de psicologia, neurologia e neurociência

\footnotetext{
${ }^{2}$ Utiliza-se aqui o termo aprendizagem, referindo-se à aquisição de conhecimento de qualquer espécie e, por extensão, à aquisição de conhecimento linguístico ou metalinguístico, por meio de instrução formal ou de experiências vivenciadas. O termo aquisição é utilizado como sinônimo de "acumulação / ganho de conhecimento" através de aprendizagem.
} 


\section{Stanich, K.; Meireles, S. - Processamento cognitivo}

mencionam prazos de minutos, de vinte e quatro horas e até de anos para a consolidação de itens da memória.

Acreditamos que, seguindo-se esse modelo, muitos exemplos da experiência prática com o ensino/aprendizagem de LEs fiquem sem explicação. O simples fato de uma informação sobre a língua estar presente na memória de longa duração, como proposto pelos autores citados anteriormente, não faz com que ela seja utilizada de forma automática durante a produção em LE. Um exemplo comumente percebido e relatado é a utilização do pronome $i h r$ ( $2^{a}$. pessoa do plural, informal): em situação de sala de aula, os alunos geralmente praticam muito mais a declinação do pronome $d u\left(2^{\mathrm{a}}\right.$. pessoa do singular, informal) e do pronome Sie ( $2^{\mathrm{a}}$. pessoa, singular ou plural, formal), pois dirigem-se principalmente a um colega ou a um professor. Nos países de língua alemã, o pronome Sie formal é utilizado normalmente em sala de aula, nos diálogos entre professores e alunos adultos. No Brasil, no entanto, muitas vezes preferimos utilizar um tratamento mais informal e, portanto, quando falamos com a classe ou com mais de um aluno, utilizamos a $2^{\mathrm{a}}$. pessoa do plural, informal, $i h r$. Ouvimos inclusive relatos de vários professores (falantes não-nativos do alemão) sobre a sua necessidade de treinar essa questão especificamente antes de iniciar um curso para conseguir utilizar esse pronome em sala de aula com as declinações corretas. Muitas vezes, esses professores têm experiências de vários anos no ensino da língua alemã e estão acostumados a expor as tabelas de declinação no quadro, sem necessidade de consulta a qualquer material. Seria estranho pensar que tais tabelas ainda não estão em suas memórias de longa duração e que, por isso, eles ainda não têm esse conhecimento automatizado.

Em contraste, falantes nativos, assim como não-nativos que passaram muito tempo em países de língua alemã mas tiveram pouco contato com o ensino formal, utilizam as declinações mais comuns praticamente sem dificuldades em suas produções linguísticas, mas são incapazes de montar uma tabela de declinações. Alunos principiantes, desde as primeiras aulas, utilizam expressões como mit mir (“comigo"), für mich ("para mim"), wie geht's dir? (“como vai você?”) com as devidas declinações, sem tê-las ainda aprendido de modo sistemático. É comum também que, após conhecerem as tabelas e todo o sistema de declinação, os alunos produzam algumas expressões com as declinações corretas, sem hesitação, mas parem, após a produção, para analisar o que produziram e constatar que as produziram corretamente. 


\section{Stanich, K.; Meireles, S. - Processamento cognitivo}

No caso dos professores que, apesar de terem memorizado todas as tabelas de declinação, podem ter dificuldade no uso de uma ou outra declinação em sua produção linguística, considera-se que as tabelas estejam realmente consolidadas em suas memórias. No entanto, o que permite o uso fluente desse conhecimento é a frequência da utilização dos dados linguísticos referentes aos conteúdos dessas tabelas, relacionados ao contexto em que são utilizados. Essa prática forneceria as informações necessárias para a formação de outro tipo de memória, menos consciente e mais automatizada. Não seria, portanto, o ato de lembrar a regra ou a tabela que se tornaria mais rápido ou automático, mas sim, uma outra informação, com outro formato, estaria em uso no momento da fluência verbal. Como vimos nos tópicos anteriores, a capacidade de uso fluente do conhecimento linguístico estaria relacionada à formação e ao uso da memória não-declarativa, por meio da construção e do processamento de unidades significativas prontas para uso. A passagem "automática" de informações explícitas sobre a língua e suas regras do sistema de memória de curta para o de longa duração, como propõe MCLAUGHLIN, ou de um sistema de conhecimento explícito para um de conhecimento implícito, como propõe BIALYSTOK (1978), não explica a capacidade de uso fluente da língua.

Neste artigo, apresentamos a hipótese de que os dois níveis ou processos de aprendizagem descritos de várias formas em teorias da linguagem (KRASHEN 1977, 1982, 1985; MCLaughlin 1978; BialystoK 1978; SinClaiR 1988; KLEIN 1992, entre outros) relacionam-se a diferentes sistemas da memória humana, que se diferenciam não pelo tempo de armazenamento (memórias de curta e longa duração), mas pelo tipo ou formato da informação armazenada.

Memória declarativa indica um sistema de conhecimento no qual as informações representadas são explicitamente acessíveis em forma de fatos e dados e podem ser conscientemente evocadas, isto é, o indivíduo tem acesso consciente ao conteúdo da informação. Subdivide-se em memória para fatos (ou memória semântica) e memória para eventos (ou memória episódica).

Em oposição, o termo memória não-declarativa abrange habilidades e vieses no desempenho que não podem ser explicitamente acessados e manifestam-se apenas sob a forma de desempenhos comportamentais, adquiridos gradualmente ao longo de diversas experiências. Subdivide-se em habilidades e hábitos (nas modalidades motora, perceptual e cognitiva), pré-ativação (ou indução, alteração do desempenho em função de material 


\section{Stanich, K.; Meireles, S. - Processamento cognitivo}

previamente apresentado), condicionamento clássico (memória de associações emocionais e memória de associações motoras) e aprendizagem não-associativa (adaptação a estímulos que deixaram de ter importância ou ganharam importância).

Resumindo, podemos dizer que a memória declarativa pode ser compreendida como um "saber que" e a memória não-declarativa, como um "saber como" (cf. XAVIER 1996).

Segundo trabalhos desenvolvidos na área de neurocognição da linguagem, a memória declarativa estaria relacionada ao conhecimento explícito do léxico e de regras da língua. A memória não-declarativa, por sua vez, seria responsável pelas habilidades motoras da linguagem e pelo processamento de representações de sequências frequentes na língua, utilizadas como expressões prontas (aqui denominadas chunks), sem a necessidade de composição em tempo real (cf. BYBEE 2002; ULLMAN 2001; ULLMAN et al. 2002).

Podemos relacionar diversos fatores envolvidos na aprendizagem de uma língua a um ou a vários desses subsistemas da memória. A habilidade para pronunciar uma certa sequência de fonemas, por exemplo, estaria relacionada ao sistema de habilidades e hábitos, mas, se a sequência for uma palavra conhecida, estará também relacionada à memória semântica. A capacidade de indução estaria relacionada ao sistema de pré-ativação (priming - uma facilitação inconsciente ou viés no desempenho em decorrência da exposição prévia às informações); por exemplo, uma única exposição a uma palavra pode ser suficiente para facilitar seu processamento horas depois.

A interação social estaria relacionada tanto à memória episódica (a memória de uma determinada situação de interação, por exemplo), quanto à memória de associações emocionais. Fatores psicológicos como motivação e identidade estariam também diretamente relacionados à memória emocional e à episódica. Considerando-se as inúmeras possibilidades de combinação de fatores na aprendizagem de uma língua e as experiências individuais de cada aprendiz, as combinações de relações e interações entre os sistemas seriam infinitas, como no modelo de aquisição da linguagem proposto por PAIVA (2005).

Desses sistemas de memória, o denominado sistema de memória declarativa estaria relacionado ao conhecimento consciente (explicitável) sobre a língua e suas regras. O sistema de não-declarativa, por sua vez, seria responsável pelo processamento de informação de forma involuntária e pela habilidade de uso da língua na comunicação através da automatização de regras (cf. SQuire e ZolA-Morgan 1988, 1991). A noção de independência entre os sistemas de memória é bastante consensual nos estudos de 


\section{Stanich, K.; Meireles, S. - Processamento cognitivo}

neurociências, sendo reforçada pela dissociação entre os tipos de prejuízo de memória de longa duração apresentados por pacientes amnésicos e parkinsonianos: enquanto pacientes amnésicos apresentam prejuízo de memória declarativa, pacientes com doença de Parkinson apresentam prejuízo específico de funções de memória não-declarativa, pelo menos nos estágios iniciais da doença.

Com base nesta distinção entre os sistemas de memória, propõe-se aqui um modelo teórico para o processamento cognitivo relacionado à produção em língua estrangeira, fundamentado em teorias recentes da neurociência sobre memória, aprendizagem e processamento de representações de sequências frequentes na língua (chunks). A hipótese aponta novas interpretações para questões sobre produção em língua estrangeira, como automatização do conhecimento, criatividade, papel do output e papel da instrução.

\section{Aprendizagem de língua estrangeira e processos cognitivos}

Ao acompanharmos o percurso das teorias e abordagens em aquisição da linguagem, do behaviorismo ao sócio-interacionismo, passando pelo inatismo e pelo construtivismo, entre outras, vemos que essas teorias e abordagens procuram explicar a aprendizagem de línguas focando aspectos diferentes (cf. p. ex.: SCARPA 2001; GUEDES EVANGELISTA 2003: 83s.). Fatores cognitivos, sociais ou emocionais são vistos, muitas vezes, como fatores independentes, de maior ou menor importância, ou mesmo de importância incalculável, e por isso são ignorados. Daí resultam visões fragmentadas, que dificultam a compreensão global do processo complexo que é a aprendizagem de línguas.

No entanto, nota-se que há aspectos congruentes nos vários trabalhos e uma convergência desses estudos para determinados pontos, como a tendência a se considerar a aprendizagem de línguas como dinâmica, complexa e composta de múltiplos fatores que se combinam e a existência de diferentes modos de processamento e aprendizagem. LARSENFREEMAN (1997) foi a primeira a abordar essa complexidade à luz da teoria dos sistemas complexos ou teoria do caos. Essa teoria afirma que a natureza é um sistema complexo composto por outros sistemas igualmente complexos, não-lineares, dinâmicos, caóticos, imprevisíveis, sensíveis às condições iniciais, abertos e adaptativos, pois têm capacidade de auto-organização. A autora apresenta várias evidências para comprovar que há semelhanças 


\section{Stanich, K.; Meireles, S. - Processamento cognitivo}

entre esses sistemas e a aquisição de segunda língua (L2), entre elas, a dinamicidade do processo de aprendizagem, sua complexidade, a não-linearidade e a auto-organização da interlíngua. Como afirma PAIVA (2005: 24), considerando esses conceitos da teoria do caos/complexidade, LARSEN-FREEMAN reúne, por exemplo, o cognitivismo e o sóciointeracionismo, postulando que "tanto a criatividade individual quanto a interação social se combinam para influenciar a moldagem da gramática em desenvolvimento"3.

A capacidade humana de apreender o mundo e expressar-se através da linguagem está intimamente ligada ao funcionamento de uma sofisticada rede de neurônios interconectados, que nos permite falar, entender o discurso de outras pessoas e, também, pensar. Estas atividades requerem uma grande estrutura neurológica, que nos capacita não só a armazenar dados correspondentes a milhares de unidades lexicais e diversas estruturas sintáticas, mas também a fazer interconexões entre elas e o mundo em que vivemos, seja ele um mundo físico, social ou afetivo que compartilhamos com nossos semelhantes. No entanto, em que pese o grande progresso realizado nesse campo, ainda há muito poucas unanimidades sobre a interface entre a linguagem e o sistema neurológico.

Do ponto de vista da linguística, diversas correntes surgidas a partir da década de 1970 ocupam-se da linguagem humana a partir de uma perspectiva fortemente influenciada pelas novas descobertas da psicologia e das neurociências. Essas correntes, frequentemente reunidas sob o termo geral de linguística cognitiva (veja, p.ex., SCHWARZ 1992), propõem uma investigação das línguas à luz de esquemas comportamentais e sistemas de apreensão da realidade e estruturação da informação apoiados em dados biológicos e processos mentais de cunho geral, como, por exemplo, os estudos elaborados no departamento de neurocognição da linguagem do Instituto Max Planck de neurociências cognitivas em Leipzig / Alemanha, sobre o processamento semântico-conceitual (FrIEDERICI; StEINHAUER \& PFEIFER 2002; HAHNE 2001; HAHNE \& FRIEDERICI 1998, 2001).

O objeto de estudo é a linguagem enquanto fenômeno mental, ou seja, todos os componentes da capacidade humana de comunicar-se através da linguagem. Para tanto, procura incorporar aspectos da competência procedural, em especial a análise de pontos comuns entre o sistema linguístico e outros sistemas; a noção de competência linguística passa a abranger também os mecanismos que permitem colocar em prática o conhecimento

\footnotetext{
${ }^{3}$ Tradução de Vera Lúcia M. de Oliveira e Paiva: “...both individual creativity and social interaction combine to influence the shape of the developing grammar.” (Paiva 2005: 24)
} 


\section{Stanich, K.; Meireles, S. - Processamento cognitivo}

linguístico, definindo a capacidade linguística do ser humano tanto em termos estruturais (no sentido de sistema mental do conhecimento) como procedurais (no sentido de mecanismo processador).

A linguística cognitiva considera a linguagem como uma faceta integral da cognição, e não como um módulo isolado. Tanto quanto possível, é vista como acessando fenômenos cognitivos de caráter mais geral, tal como atenção, percepção, categorização e memória, dos quais não pode ser dissociada: uma língua é entendida como um inventário estruturado de unidades linguísticas convencionais; uma unidade, por sua vez, é um padrão de atividade de processamento dominado (mastered) completamente pelo indivíduo e pode, assim, ser executado de modo mais ou menos automatizado, caracterizando uma "rotina cognitiva". O conhecimento linguístico reside em "pacotes" rotinizados de atividade de processamento, alguns dos quais são ativados como parte do processamento geral executado pelo sistema como um todo ao produzir ou entender novas expressões. É através do constante impacto do uso que unidades linguísticas se mantêm e se desenvolvem: a ativação de uma unidade reforça-a e aumenta progressivamente a sua fixação; por outro lado, uma unidade que não é explorada tende a "decair" e pode finalmente perder-se. Através de procedimentos de elaboração e extensão, as unidades geram variações que podem assumir uma vida própria. Sincronia e diacronia são inseparáveis nessa perspectiva baseada no uso (cf. LANGACKER 2007: 425-431).

Com base nestas considerações, o próximo tópico focaliza mais detalhadamente as interações entre aprendizagem e sistemas de memória, como pressupostos para a proposta de um modelo dos processos que guiam a aprendizagem de línguas estrangeiras.

\section{Aprendizagem e memória}

Embora seja comum referir-se à memória como uma entidade única, a maioria dos modelos cognitivos atuais trabalha com a noção de múltiplos componentes, aos quais são atribuídas funções diversas. Aqui, consideramos a hipótese de que os dois níveis ou processos de aprendizagem descritos de várias formas em teorias da linguagem (KRASHEN 1977, 1982, 1985; MCLaughlin 1978; BialystoK 1978; SinClaiR 1988; KLeIN 1992, entre outros) relacionam-se a diferentes sistemas da memória humana, que se diferenciam não pelo tempo 


\section{Stanich, K.; Meireles, S. - Processamento cognitivo}

de armazenamento (memórias de curta e longa duração), mas pelo tipo ou formato da informação armazenada. Para efeito de simplificação, conforme proposto por SQUIRE e ZOLAMoRGAn (1988, 1991), esses diferentes sistemas de memória serão aqui denominados de declarativo e, em oposição, não-declarativo. Ambas são consideradas como sistemas da memória de longa duração mas, segundo MAGILA \& XAVIER (2000), esses sistemas possuem diferenças evidentes quanto ao formato da informação representada.

Memória declarativa indica um sistema de conhecimento no qual as informações representadas são explicitamente acessíveis em forma de fatos e dados e podem ser conscientemente evocadas, isto é, o indivíduo tem acesso consciente ao conteúdo da informação. Em oposição, o termo memória não-declarativa abrange habilidades e vieses no desempenho que não podem ser explicitamente acessados e manifestam-se apenas sob a forma de desempenhos comportamentais. Esse tipo de informação seria adquirido gradualmente ao longo de diversas experiências. Em resumo, podemos dizer que a memória declarativa pode ser compreendida como um "saber que" e a memória não-declarativa, como um "saber como" (cf. XAVIER 1996). Conforme proposto por SQUIRE e ZOLA-MORGAN (1988, 1991), a memória declarativa subdivide-se em memória para fatos (ou memória semântica) e memória para eventos (ou memória episódica) e estaria relacionada ao conhecimento explícito do léxico e de regras da língua. A memória não-declarativa, por sua vez, seria responsável pelas habilidades motoras da linguagem e pelo processamento de representações de sequências frequentes na língua, utilizadas como expressões prontas (aqui denominadas chunks), sem a necessidade de composição em tempo real (cf. BYBEE 2002; ULLMAN 2001; ULLMAN et al. 2002), e que desempenham um papel fundamental na armazenagem e na organização da informação.

\section{Chunks - unidades significativas da memória}

O fenômeno de agrupamento (chunking) pode ser verificado no processamento de informação de diversos tipos, por exemplo, quando agrupamos os algarismos de um número telefônico para facilitar a memorização. Ações como jogar tênis ou tocar piano também são guiadas por representações estruturais que organizam a sequência de movimentos em chunks, em unidades integradas. Um claro exemplo dessa organização é encontrada na notação 


\section{Stanich, K.; Meireles, S. - Processamento cognitivo}

musical, na qual as partituras representam tais unidades como frases musicais contendo temas ou motivos completos, os quais devem ser executados e interpretados como uma unidade e podem ser comparados a sintagmas ou frases na linguagem verbal.

Uma consequência interessante do processo de chunking é que, através desse processo, a informação agrupada pode também ser decomposta em mais itens de informação do que se poderia normalmente reter na memória. Por exemplo, ao reter na memória sete palavras de dez letras cada, podemos decompô-las em setenta letras, usando o conhecimento sobre como soletrar palavras, e assim armazenar na memória uma quantidade de letras muito superior ao limite normal. Essa característica evidencia a habilidade humana de codificar informação em "pacotes", que podem ser "manuseados" ou processados com agilidade e rapidez (como num programa de compactação de arquivos no computador) dentro do limite da memória (cf. GAZZANIGA et al. 2002: 307, 458). Outra característica interessante é que o limite se refere à quantidade de chunks, mas não ao seu conteúdo. Conclui-se que, para o registro da informação como um chunk, não há um limite para o tamanho dessa informação, desde que forme uma unidade.

Segundo PAWLEY \& SYDER (1983), no processamento da linguagem, a memória de longa duração armazena sequências frequentes como unidades significativas prontas para uso, que podem ser acessadas e utilizadas sem a necessidade de processamento ou composição "online" pela seleção de fonemas, palavras ou recordação de regras gramaticais explícitas. Nos estudos da linguagem e aquisição da linguagem, tais unidades significativas têm recebido diferentes denominações, a partir de várias abordagens do tema, incluindo speech formulae (PETERS 1983), lexicalized sentence stems (PAWLEY \& SYDER 1983), lexical phrases (NATTINGER \& DECARRICO 1992), ready made units (COWIE 1992) e formulaic sequences (WRAY 2000, 2002). Com base em SinClAIR (1991) e WrAY (2002), o termo chunk é aqui utilizado como uma sequência frequente na língua, contínua ou descontínua, de fonemas, palavras ou grupos de palavras, que é mantida e evocada da memória como uma unidade, não sendo sujeita à formação ou análise gramatical e abrangendo aspectos motores, semânticos e, inclusive, afetivos e situacionais, relacionados à adequação e a relevância da expressão para o falante.

Como são registrados não como uma sequência ordenada de unidades linguísticas, mas como um elemento único e coeso, pode-se supor que os chunks pertençam ao mesmo domínio que as fórmulas de rotina e expressões estereotipadas que caracterizam o discurso automático. 


\section{Stanich, K.; Meireles, S. - Processamento cognitivo}

Os chunks compreendem também diferentes fatores pragmáticos, sociais e culturais, os quais são registrados como um único bloco de informação. O próximo item evidencia a sua importância para a produção linguística e propõe um modelo de processamento cognitivo relacionado à produção em língua estrangeira que permita a visualização de processos nela envolvidos.

\section{Um modelo teórico para o processamento cognitivo relacionado à produção em língua estrangeira}

Conforme exposto nos tópicos anteriores, a capacidade de uso fluente do conhecimento linguístico estaria relacionada à formação e ao uso da memória não-declarativa, por meio da construção e do processamento de unidades significativas prontas para uso. A passagem "automática" de informações explícitas sobre a língua e suas regras do sistema de memória de curta para o de longa duração, como propõe MCLAUGHLIN, ou de um sistema de conhecimento explícito para um de conhecimento implícito, como propõe BIALYSTOK , não explica a capacidade de uso fluente da língua.

Considerando o conhecimento de regras, tabelas, listas de vocabulário e qualquer conhecimento teórico sobre a língua como um formato diferente de informação, registrado na memória declarativa, esta forma de conhecimento auxiliaria ou aceleraria a formação da informação automatizada, não se transformando nela, mas direcionando a atenção para os dados correspondentes no input linguístico e até mesmo fornecendo elementos para a formação de novos dados, ausentes no input, como veremos a seguir. Somente a prática da produção linguística e o uso da criatividade permitiriam ao aprendiz e mesmo ao falante considerado proficiente utilizar com fluência as expressões aprendidas através do input e criar expressões novas. A frequência da produção dessas expressões forneceria aos sistemas de processamento e memória uma unidade compilada de informações motoras (relacionadas com a pronúncia e articulação dos fonemas) e informações sobre o significado, a adequação e a relevância de cada expressão. Essa compilação estaria potencialmente preparada para o armazenamento na memória e para sua retomada e reutilização, sem o esforço cognitivo de composição de toda a expressão em tempo real. 


\section{Stanich, K.; Meireles, S. - Processamento cognitivo}

Retomando os conceitos de memória operacional, memória declarativa e memória não-declarativa e lembrando ainda os conceitos de input, output e intake (este último considerado o processo de internalização do input), apresentamos uma representação gráfica do modelo que proponho para o processamento cognitivo relacionado à produção em LE. $\mathrm{O}$ modelo se refere, a princípio, tanto a aspectos da aprendizagem e da produção em LE quanto em língua materna (LM). No entanto, vamos nos concentrar nas considerações sobre a produção em LE. Os exemplos aqui apresentados referem-se a aprendizes adultos de alemão como LE, sem contato anterior com o idioma fora do ambiente de ensino formal.

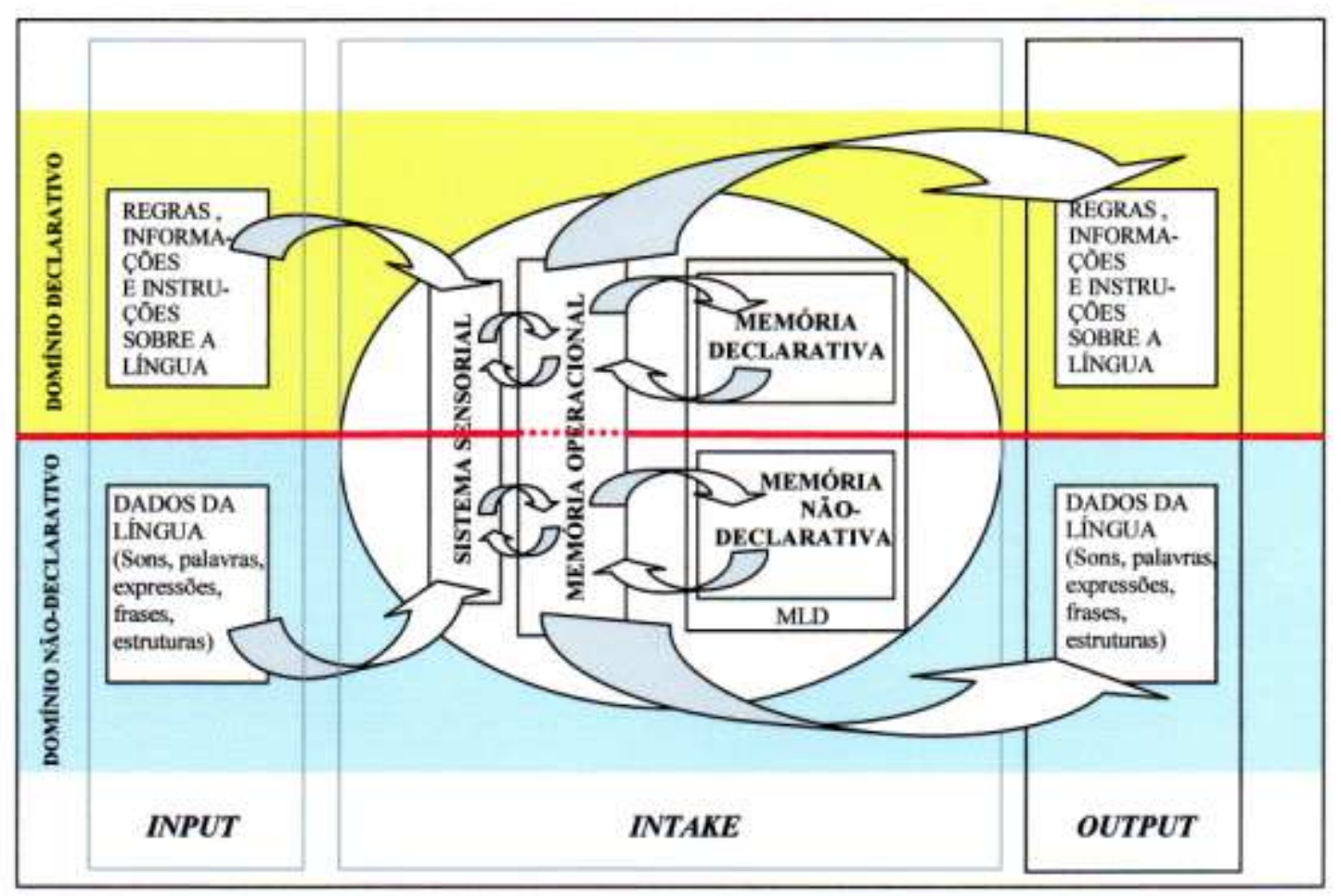

A parte superior do modelo, que denominamos domínio declarativo, representa a memória declarativa, os dados do input que potencialmente seriam processados nesse domínio (regras explícitas e instruções sobre a língua) e os dados do output, retomados e reconstruídos após o processamento na memória operacional. Os dados do output, tal como no input, se apresentam na forma de regras explícitas e conhecimento teórico sobre a língua. A parte inferior do modelo, denominada domínio não-declarativo, representa a memória não-declarativa, os dados linguísticos do input potencialmente processáveis como unidades significativas (ou 


\section{Stanich, K.; Meireles, S. - Processamento cognitivo}

chunks) e os dados linguísticos do output. Para efeito de simplificação, nos campos input, intake e output, o modelo mostra apenas dados linguísticos e dados sobre a língua, respectivamente nos domínios não-declarativo e declarativo. No entanto, considero também a presença de diversos fatores extralinguísticos (elementos culturais, experiências individuais, fatores sociais etc.), apesar de não representados no modelo.

As setas no sentido input - sistema sensorial mostram a percepção dos dados do input. Os dados que efetivamente alcançam o sistema sensorial são ainda selecionados ou filtrados pela memória operacional, segundo critérios não-conscientes, relacionados à relevância e à capacidade de processamento. Essa seleção é representada pelas setas que partem da memória operacional e retornam em direção a ela.

Vamos agora examinar mais detidamente os dois grandes domínios que compõem o modelo.

\section{O domínio não-declarativo}

A parte do modelo aqui denominada domínio não-declarativo representa o processamento de dados da língua (sons, palavras, expressões, frases, estruturas) provenientes do input, a reprodução desses dados na produção (output) e a geração de novos dados no sistema de memória de longa duração não-declarativa. Por "geração de novos dados na memória" é possível entender também "armazenamento de novos dados na memória”. No entanto, em conformidade com estudos de neurociência (p. ex.: CARLSON 2002: 424), consideramos a memória não como um conjunto de dados armazenados, mas como um conjunto de modificações na rede neuronal, decorrentes da experiência e do aprendizado. Os dados provenientes do input não são "armazenados", mas processados de forma a gerar novas representações que modificam as redes neuronais.

$\mathrm{Na}$ representação gráfica do domínio não-declarativo, a seta no sentido input $\rightarrow$ sistema sensorial mostra a percepção dos dados do input (visuais, auditivos e sensoriais em geral). Os dados que alcançam o sistema sensorial são ainda selecionados ou "filtrados" pela memória operacional, segundo critérios não-conscientes, relacionados à capacidade de processamento e à relevância. No modelo, essa seleção é representada pelas setas no sentido sistema sensorial $\rightarrow$ memória operacional e no sentido memória operacional $\rightarrow$ sistema sensorial. 


\section{Stanich, K.; Meireles, S. - Processamento cognitivo}

O processamento se dá nas duas direções. A percepção é também influenciada pelo trabalho da memória operacional: por terem experiências e memórias diferentes, os indivíduos podem ter também uma percepção diferente do mesmo input.

A seta no sentido memória operacional $\rightarrow$ output, mostra que, posteriormente, o processamento na memória operacional permite a reprodução dos dados do intake na produção. Podemos ilustrar esses processos com um exemplo simples de uma frase que alunos de alemão geralmente aprendem nas primeiras aulas e logo estão aptos a reproduzir (ex. 1) ou, ainda, com uma resposta imediata repetitiva (ex. 2).

Ex. 1:

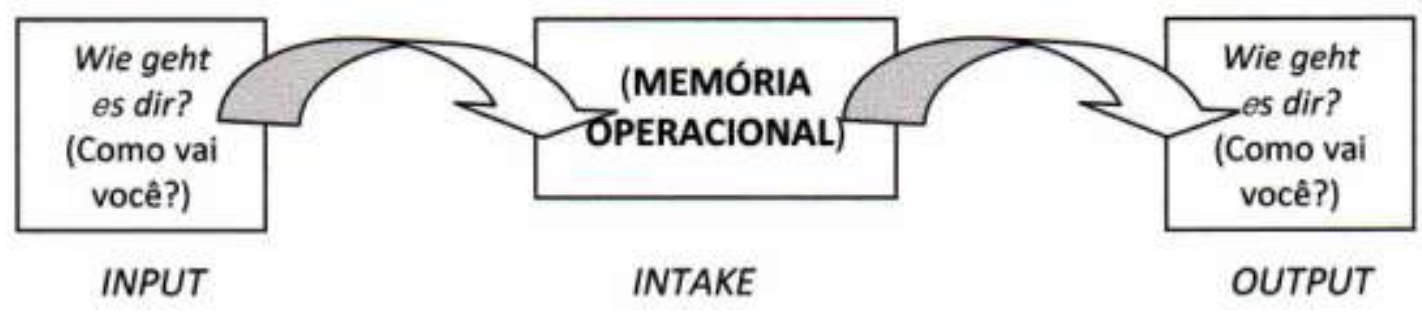

Neste exemplo, consideramos o output como mera repetição do input recebido.

Ex. 2:

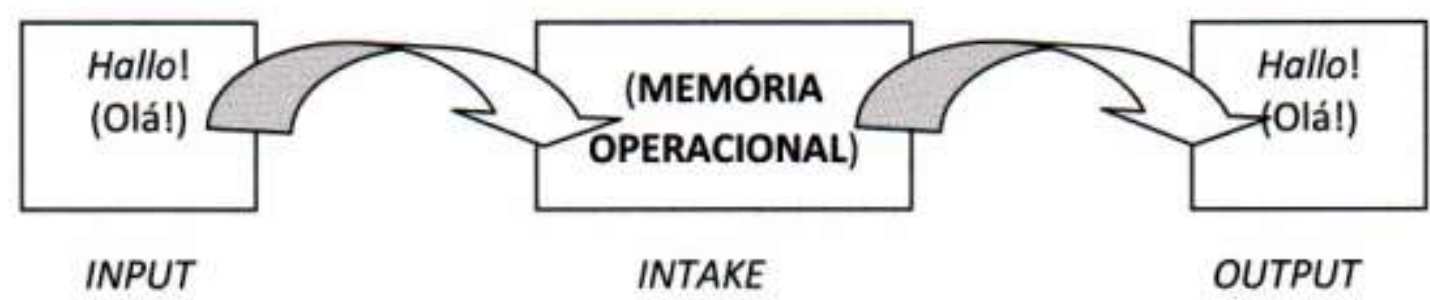

Neste segundo exemplo, somente se assumirmos que o falante, assim como uma criança que ainda aprende a falar, simplesmente repete ou imita o que foi ouvido, sem um processamento mais complexo ou reflexão a respeito da adequação do que diz, podemos considerar a resposta imediata como mera repetição do input recebido. Obviamente, na maioria dos casos, não é isso o que ocorre. O falante precisa escolher o que dizer em determinada situação ou decidir qual a resposta adequada a uma determinada pergunta. Para tanto, a memória operacional não 
Stanich, K.; Meireles, S. - Processamento cognitivo

trabalha apenas processando os dados provenientes do input, mas também retomando e reprocessando os dados da memória de longa duração, como mostra o próximo exemplo.

Ex. 3:

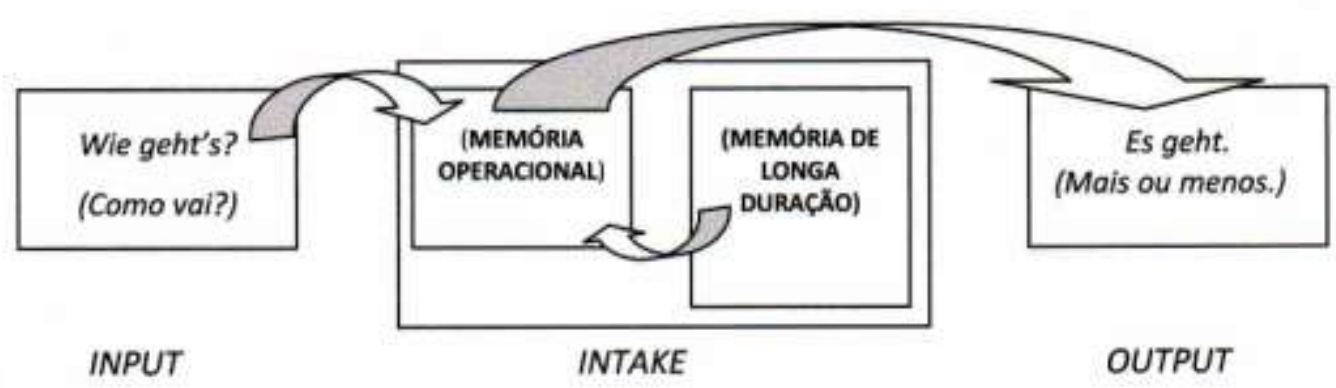

Neste caso, a resposta não pode ser considerada mera repetição do input. A fonte de dados para a resposta não é o input imediatamente recebido e sim outros dados, anteriormente recebidos e memorizados.

O processamento conjunto dos dados provenientes do input e dos dados retomados da memória de longa duração permite ainda a geração de dados originais (ou seja, não provenientes do input), que, por sua vez, podem ser utilizados no output e passar também a integrar a memória de longa duração.

No exemplo a seguir (ex. 4), o falante recebe inputs diferentes em diversas situações. O processamento desses dados juntamente com outros dados retomados da memória de longa duração permite, em uma nova situação, a produção de um dado inédito. Ex. 4:

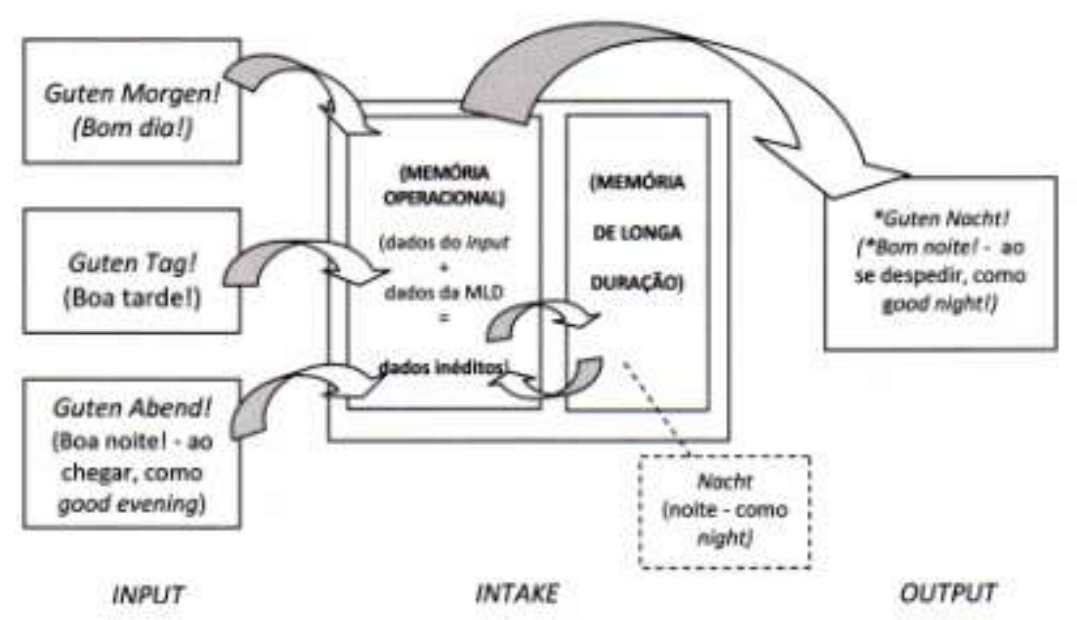




\section{Stanich, K.; Meireles, S. - Processamento cognitivo}

Neste caso, o dado inédito “Guten Nacht!” apresenta uma incorreção, já que a expressão correta seria "Gute Nacht!". O falante seria melhor sucedido se tivesse recebido do input a expressão correta "Gute Nacht" ou ainda se dispusesse de mais informações, sobre gênero e declinação, para deduzir a expressão corretamente. No entanto, mesmo incorreta, a expressão é compreensível e adequada à situação (desejar "boa noite” ao despedir-se).

Essa capacidade de escolher / mudar a resposta e de adaptar-se a novas situações, demonstra a aprendizagem e é esta, inclusive, a definição de aprendizagem adotada pelas neurociências cognitivas, a qual nos parece perfeitamente aplicável à aprendizagem de línguas. Conforme CARLSON (2002: 424), a aprendizagem é o processo pelo qual as experiências mudam nosso sistema nervoso e, assim, nosso comportamento. A função primária da capacidade de aprender é desenvolver comportamentos adaptados a um ambiente que muda constantemente. É essa mesma capacidade, entre outras, que permite ao falante chegar à fluência e adaptar-se a uma nova comunidade linguística.

\section{O domínio declarativo}

A parte superior do modelo, aqui denominada domínio declarativo, representa a aquisição consciente de conhecimentos relativos às regras, informações e instruções sobre a língua e o processamento desse tipo de informação. Tal processamento permite a geração de novos dados no sistema de memória de longa duração declarativa e a reprodução desse tipo de dado na produção. Os dados do output, assim como no input processado nesse domínio, se apresentam na forma de regras explícitas e conhecimento teórico sobre a língua e não como palavras, expressões ou estruturas da língua.

Neste ponto, é necessário frisar que, com essa divisão do input em input nãodeclarativo e input declarativo, no esquema gráfico do modelo, queremos apenas representar essa especificidade no processamento da linguagem. Obviamente, o input não se encontra “isolado", mas o processamento ocorre, sim, em sistemas separados, da mesma forma como na percepção visual de objetos, por exemplo, temos células especializadas na percepção da forma e outras especializadas na percepção da cor, e, no entanto, temos a impressão de uma percepção única. O mesmo ocorre com o output. Apenas analisando a produção, não é possível separar um output exclusivamente produzido pelo sistema declarativo de outro exclusivamente produzido pelo sistema não-declarativo. Afinal, mesmo para falar ou escrever 


\section{Stanich, K.; Meireles, S. - Processamento cognitivo}

sobre regras, o falante precisa expressar-se por meio de sons, palavras, expressões e estruturas da língua. No entanto, evidências neurofisiológicas demonstram que o processamento ocorre em sistemas separados. O output e as condições em que é produzido podem também permitir inferências sobre um maior ou menor uso de um ou de outro sistema de memória.

Podemos ilustrar os processos de aprendizagem do domínio declarativo com os seguintes exemplos:

Ex. 5:

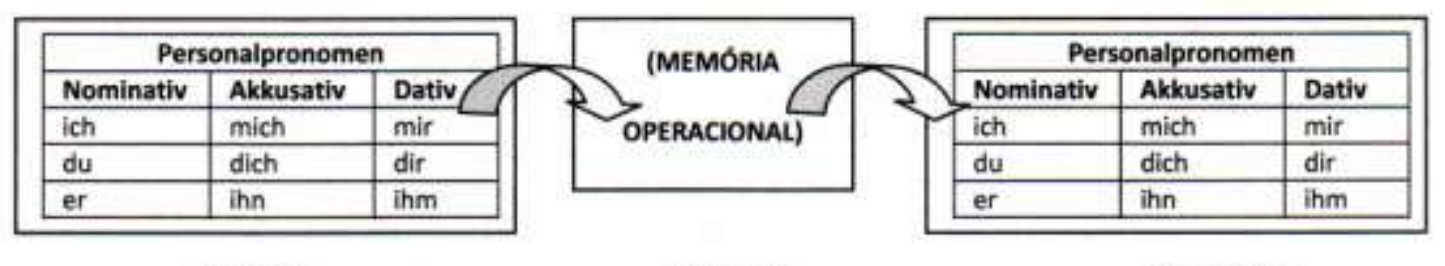

INPUT

INTAKE

OUTPUT

No exemplo 5, o aprendiz recebe como input uma tabela com a declinação dos pronomes pessoais e é capaz de reproduzi-la no output. Nos exemplos 6 e 7, um aluno aprende uma regra em uma aula ou em um livro e pode compreendê-la e reproduzi-la com suas próprias palavras.

Ex. 6:

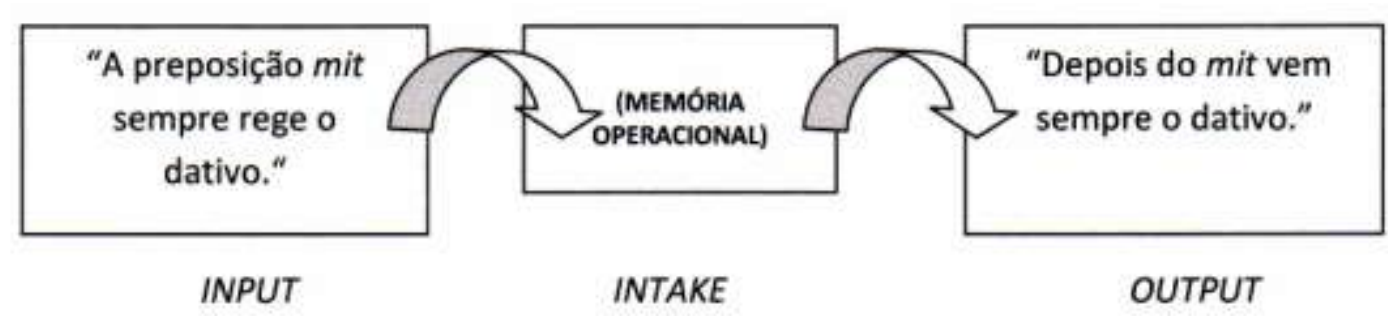

Ex. 7: 


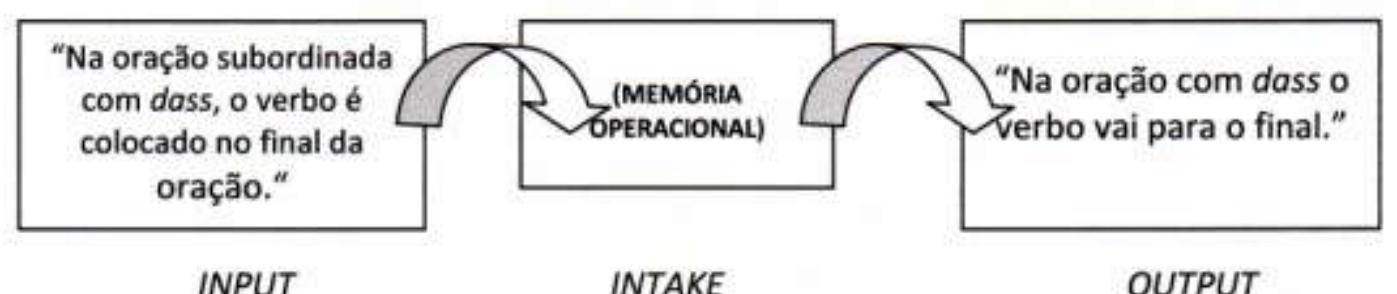

A capacidade de reproduzir a tabela do exemplo 5 e as regras dos exemplos 6 e 7 não garantem, entretanto, que o aluno seja capaz de aplicar adequadamente as instruções sintetizadas nessa tabela e essas regras em uma situação de produção linguística, como na conversação, por exemplo. Este tipo de processamento e aprendizagem produz melhores resultados quando o aluno precisa demonstrar seu conhecimento da língua através da reprodução de regras ou de outras informações teóricas, como nos exercícios com lacunas abaixo, retirados de manuais didáticos em uso atualmente em diversos cursos de alemão como LE:

Ex. 8:

Ergänzen Sie die Regel.(Complete a regra.)

Im Nebensatz mit dass steht das Verb ạm En_de. (Na oração subordinada com dass o verbo encontra-se no fin $\underline{\text { final. }}$.)

(FunK et. al. Studio D A2, 2006, p. 29)

Ex. 9:

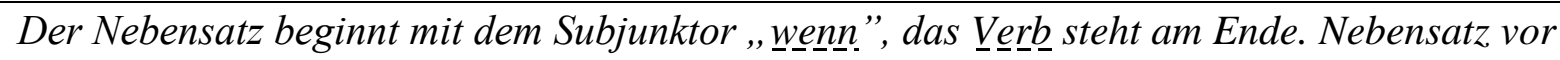
Hauptsatz: Der Hauptsatz beginnt mit dem $\underline{\text { Ver }} \underline{\text { b. }}$.

(A oração subordinada começa com a conjunção "wennn”-, o verb-

Oração subordinada antes da principal: a principal começa com o vere_bo.

(MÜLLER. Optimal A1, 2004, p. 85)

Ex. 10:

Ergänzen Sie die Regel. (Complete a regra.)

Akkusativendung im Maskulinum Singular ist immer__en. (A terminação do acusativo no masculino singular é sempre _enn.)

(FunK et. al. Studio D A1, 2006, p. 119) 


\section{Stanich, K.; Meireles, S. - Processamento cognitivo}

Da mesma forma que no domínio não-declarativo, também no domínio declarativo a memória operacional retoma dados da memória de longa duração. O processamento conjunto dos dados provenientes do input e dos dados retomados da memória de longa duração permite a geração de dados originais, que, por sua vez, podem ser utilizados no output e passar também a integrar a memória de longa duração declarativa, como mostra o exemplo a seguir (ex. 11):

Ex. 11:

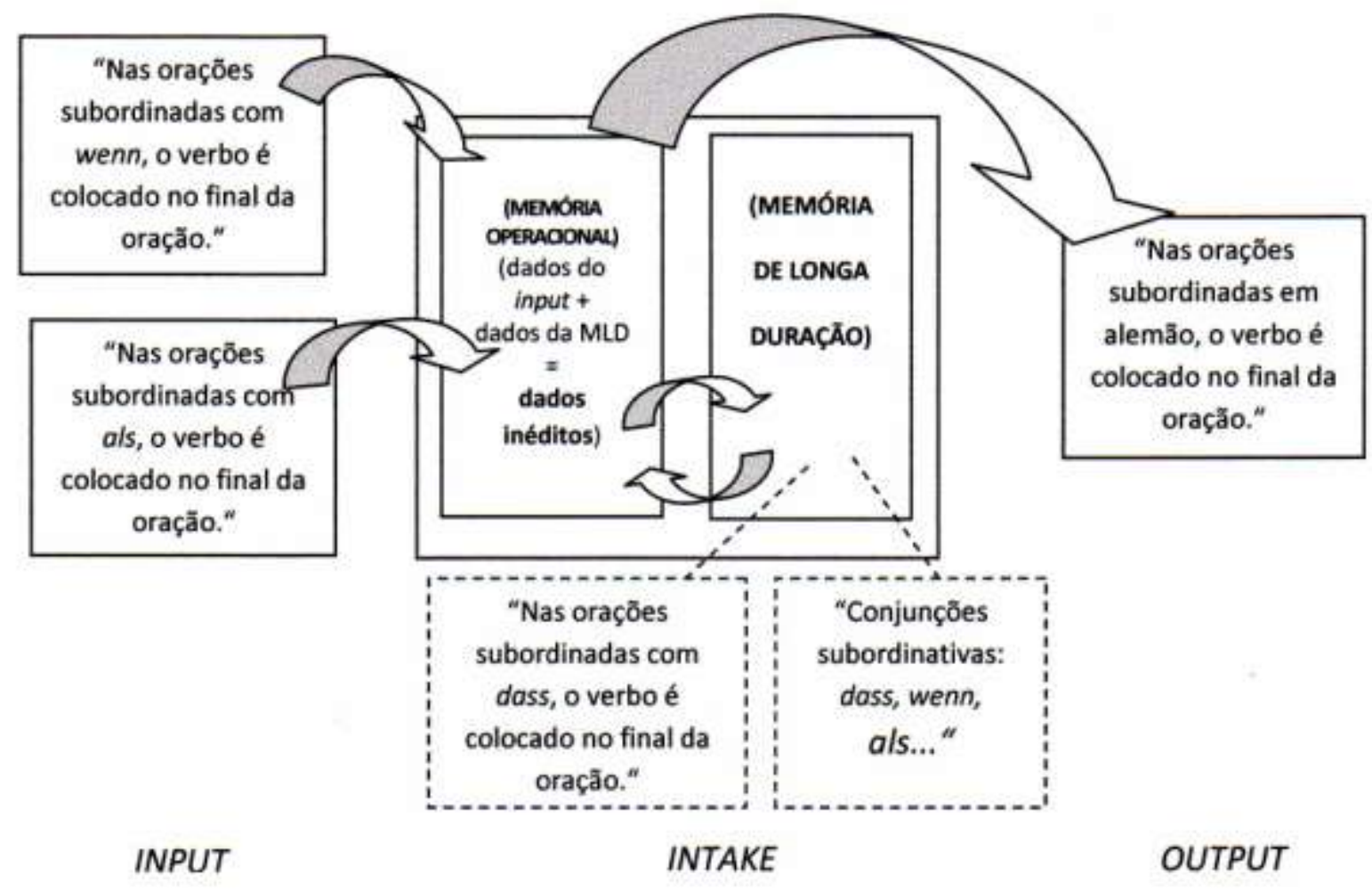

Assim, no modelo aqui proposto, temos dois domínios onde ocorrem processamentos de diferentes informações relacionadas à linguagem: o domínio declarativo, que processa e permite a aprendizagem e a produção exclusivamente de dados teóricos sobre a língua e o domínio não-declarativo, que processa e permite a aprendizagem e a produção de dados da língua propriamente ditos (sons, palavras, expressões, estruturas).

Como visto anteriormente, a memória operacional funciona como um sistema de manipulação e processamento de informações e trabalha não apenas com dados provindos do 


\section{Stanich, K.; Meireles, S. - Processamento cognitivo}

sistema sensorial, mas também com dados retomados das memórias declarativa e nãodeclarativa. No processamento da linguagem, esse sistema de memória atuaria, então, selecionando dados novos e confrontando-os com outros, já registrados nos sistemas declarativo e não-declarativo, e seria responsável também pelo envio de novos dados para esses sistemas, como indicam as setas no sentido memória operacional $\rightarrow$ memória de longa duração (MLD).

Estudos demonstram que a aprendizagem de tarefas relacionadas à memória nãodeclarativa não depende da intermediação da memória de curta duração e que a informação pode passar direto para a memória de longa duração, mesmo que o sujeito não tenha consciência dessa aprendizagem (cf. SQUIRE et al. 1992; GRAF, SQUIRE \& MANDLER 1984). No entanto, quando se utiliza o conceito de memória operacional e não o de memória de curta duração, permanecem algumas dúvidas. Alguns autores, como GRUBER \& GROSCHKE (2004), acreditam que a memória operacional seja representada por dois subsistemas com funções diferentes. Um desses subsistemas seria responsável pelo controle cognitivo e o outro estaria relacionado à manutenção da informação. Seguindo-se esse modelo, se considerarmos que a execução de qualquer tarefa cognitiva depende de algum tipo de controle, mesmo que nãoconsciente, considero ser viável a hipótese de que a aprendizagem e execução de tarefas linguísticas relacionadas à memória não-declarativa dependa do subsistema de controle da memória operacional, mesmo que não necessite de manutenção temporária e consciente no outro subsistema.

Como mostra o esquema, nenhuma seta cruza a linha que separa os domínios declarativo e não-declarativo. Apenas no processamento na memória operacional os dados de um e de outro domínio estão em contato. As novas informações geradas a partir desse contato podem vir a integrar o sistema de memória declarativo ou o sistema não-declarativo. As memórias declarativas, portanto, não se transformam em memórias não-declarativas, mas podem auxiliar ou acelerar sua formação, direcionando a atenção para os dados correspondentes no input linguístico ou fornecendo elementos para a formação de novos dados linguísticos, ausentes no input. Em outras palavras, a possibilidade de confronto, na memória operacional, entre dados do input e dados já registrados na memória de longa duração e ainda entre dados do domínio declarativo e do não-declarativo, permite a criação de outros dados, originais, que, por sua vez, podem passar a fazer parte da memória declarativa ou da não-declarativa. 


\section{Stanich, K.; Meireles, S. - Processamento cognitivo}

Os dados de um domínio, portanto, não podem "passar" simplesmente de um domínio para o outro, como propõe BIALYSTOK (1992), quando se refere à passagem da informação de um sistema de conhecimento explícito para um de conhecimento implícito. Tampouco trata-se da passagem da memória de curta duração (ou operacional) para a de longa duração, como propõe MCLAUGHLIN (1992), já que tanto o sistema de memória declarativa quanto o sistema de memória não-declarativa são partes da memória de longa duração.

Aprendizagens diversas ativam os mesmos sistemas de memória envolvidos na aprendizagem de línguas, o sistema de memória não-declarativo e o sistema de memória declarativo. Nesse ponto, apesar de suas especificidades em outros aspectos, a aprendizagem de línguas é muito semelhante à aprendizagem de outras habilidades cognitivas e motoras. A compreensão desse fato pode trazer contribuições para a aprendizagem e o ensino de línguas, além de permitir, na medida de sua utilidade, o uso de estratégias de ensino e de aprendizagem e de técnicas de investigação similares às utilizadas para outras habilidades.

O que pretendemos destacar aqui é que a aprendizagem de habilidades - vistas como a capacidade de executar ações ou sequências de ações com determinado propósito, de forma automatizada - é papel da memória não-declarativa. Não se adquire uma habilidade se não for de forma não-declarativa, utilizando o sistema de memória não-declarativa, segundo seu modo de funcionamento próprio. A aprendizagem declarativa de regras e teorias, por sua vez, é papel da memória declarativa, com seu funcionamento diverso, que envolve a consciência da aprendizagem e que pode auxiliar o sistema de memória não-declarativa, mas que não leva diretamente à aprendizagem de habilidades.

\section{Aspectos relacionados à aprendizagem de LE}

Em nosso modelo, identificamos a produção fluente em língua estrangeira não com um aumento na capacidade de acessar mais rapidamente dados declarativos a fim de produzir dados linguísticos adequados a uma situação de comunicação, mas sim, com a automatização de sequências motoras não acessíveis conscientemente. Automatizar o conhecimento linguístico, aumentando a fluência na produção, significa ser capaz de utilizar expressões e estruturas prontas para uso de forma espontânea e sem diminuição da velocidade normal de fala/escrita, sem a necessidade de recorrer conscientemente a regras formais. Essa automatização ocorre no domínio não-declarativo, de forma não-consciente e involuntária. 


\section{Stanich, K.; Meireles, S. - Processamento cognitivo}

Propomos que os diferentes dados apenas entram em contato na memória de processamento. Assim, não há transformações de um tipo de dados para o outro, ou transposição de dados do domínio declarativo para o não-declarativo e vice-versa, mas ambos podem ser utilizados como meios para a criação de novos dados linguísticos ou sobre a língua, o que nos levou ao detalhamento de cinco aspectos no modelo, cujos resultados principais são expostos a seguir. Em STANICH 2008 (disponível online na Biblioteca de Teses da USP), encontra-se o detalhamento completo de cada aspecto, bem como sua ilustração com exemplos a partir da aprendizagem do alemão como LE provenientes de várias fontes (materiais didáticos, experiência própria como aprendiz e professor de alemão como LE, relatos de outros professores, testes de produção escrita e entrevistas).

O primeiro aspecto é a reprodução de dados provenientes do input, no domínio nãodeclarativo. O esquema gráfico do modelo representa a percepção dos dados do input, o processamento na memória operacional e a produção por simples imitação ou pela retomada de dados da memória de longa duração. Destaca-se a importância dos chunks como unidades significativas da memória e no processamento cognitivo, segundo a perspectiva da neurociência e da linguística. Além da importância da frequência (isto é, da repetição), unidade, ordem e ritmo são características fundamentais para a formação e acessibilidade dos chunks.

O segundo aspecto refere-se à automatização do conhecimento. A ocorrência frequente de sequências na língua faz com que essas sejam interpretadas como relevantes pelo sistema nervoso. No domínio não-declarativo, e, portanto, de forma não-consciente e involuntária, as sequências motoras são processadas, automatizadas e associadas a informações semânticas, situacionais e afetivas. Podem, assim, ser acessadas e utilizadas rapidamente como expressões prontas, o que possibilita a fluência. É importante lembrar que os chunks podem ser formados a partir de vários elementos, desde sequências de fonemas e morfemas até blocos de texto completos, facilitando a produção linguística em todos os níveis.

O terceiro aspecto analisado é o papel da criatividade. Os processos mediados pela memória operacional permitem o cruzamento de informações dos sistemas de memória declarativa e não-declarativa e o preenchimento de chunks abertos ou descontínuos. Esses processos favorecem tanto a ocorrência de dados linguísticos originais na produção do falante quanto a produção de novos dados sobre a língua. 


\section{Stanich, K.; Meireles, S. - Processamento cognitivo}

A possibilidade de criação de dados originais, de natureza declarativa ou nãodeclarativa, mediada pela memória operacional, leva ao quarto aspecto analisado: o papel do output. A literatura sobre o tema atribui ao output cinco funções: percepção de lacunas na aprendizagem; formação, teste e avaliação de hipóteses; reflexão sobre a língua; desenvolvimento da fluência e auto-input, as quais são comentadas em relação aos aspectos analisados do modelo, destacando-se a importância do auto-input. Sugerimos que o output (mesmo quando considerado o output do sistema de processamento, não expresso na forma de linguagem escrita ou oral) é a forma de input que mais permite reforçar as conexões neuronais e intensificar os efeitos sobre a memória e a aprendizagem, por exigir uma participação mais ativa do aprendiz. Quando em situações de comunicação concreta, o auto-input vem ainda acompanhado de uma avaliação de sua eficácia ou funcionamento na comunicação, fornecida pelo feedback externo.

\section{papel da instrução}

Após chegarmos a considerações sobre a automatização do conhecimento, a criatividade e o auto-input, parece difícil não perguntar sobre o valor da instrução formal e o papel do professor. Compreender o papel do sistema de memória declarativa na aprendizagem pode nos aproximar de questões sobre o papel da instrução, seja ela formal, informal ou mesmo autodidata. Por esses motivos, como um quinto aspecto, o papel da instrução é examinado segundo os pressupostos teóricos que nortearam a elaboração do modelo proposto.

A primeira função específica que podemos supor para a instrução (e, por consequência, para o professor) é a mesma atribuída ao input processado no domínio declarativo, ou seja, fornecer ao aprendiz regras e informações teóricas, possibilitando a produção, mesmo sem fluência, enquanto o conhecimento não está automatizado na memória não-declarativa. A sua criação de possibilidades de produção e de repetição, por sua vez, favorecerá a formação de memórias não-declarativas para uso fluente na comunicação.

Contudo, o professor consciente dos processos cognitivos envolvidos na aprendizagem tem um papel muito mais significativo, que, em sua maior parte, não pode ser desempenhado pelo material didático ou pelo aluno autodidata, o de trabalhar a favor das tendências e dos processos naturais da aprendizagem, facilitando-os, promovendo-os e, na medida do possível, tornando-os mais conscientes para os aprendizes. 


\section{Stanich, K.; Meireles, S. - Processamento cognitivo}

São recursos essenciais, principalmente no ensino de línguas estrangeiras para:

a) promover a motivação;

b) fornecer feedback relevante (por exemplo, criando "regras divertidas" em situações em que não há regras, a fim de ativar fatores emocionais que reforcem a automatização);

c) analisar o material didático disponível e sua adequação ao perfil e aos objetivos dos alunos;

d) tornar explícitos aos alunos, na medida do possível, processos e estratégias de aprendizagem

\section{Considerações finais}

Acreditamos ter explicitado, com o modelo proposto, que os processos denominados aquisição e aprendizagem, assim como os processos automáticos e controlados e os módulos de conhecimento implícito e explícito, relacionam-se nessa ordem e, em muitos aspectos, com o uso das memórias não-declarativa e declarativa. No entanto, a relação entre esses módulos ou processos torna-se mais clara quando consideramos dois sistemas de memória independentes, com formatos de informação diferentes, que podem dar origem a dados originais a partir de seu processamento na memória operacional.

Muitas questões permanecem em aberto para trabalhos futuros, pois as considerações aqui apresentadas abrem infinitas possibilidades. Esperamos, com esta pesquisa, ter contribuído, de alguma forma, para diminuir a lacuna de trabalhos envolvendo linguagem e cognição voltados para a aprendizagem e não apenas para o estudo de patologias. Esperamos também que esta proposta incentive a compreensão da questão das diferenças entre o conhecimento consciente sobre a língua e suas regras e a habilidade de uso da língua na comunicação, bem como as questões adjacentes, como a automatização do conhecimento, o papel da produção e da instrução.

\section{Referências bibliográficas}


Stanich, K.; Meireles, S. - Processamento cognitivo

ATKINSON, R.C. \& SCHIFFRIN, R.M. "Human memory: A proposed system and its control processes". In: SPENCE, K. W. (Ed.). The psychology of learning and motivation: Advances in research and theory. New York, Academic Press, 1968, 89-195.

BIALYSTOCK, E. "Un modelo teórico del aprendizaje de lenguas segundas". In: LICERAS, J. M. (Ed.). La adquisición de las lenguas extranjeras. Madrid, Visor, 1992 (1a. ed. 1978), 177-192.

BYBEE, J. "Phonological evidence for exemplar storage of multiword sequences". In: SSLA 24, Cambridge, Cambridge University Press, 2002, 215-221.

CARLSON, N. R. Fisiologia do comportamento. Barueri, Manole 2002.

COWIE, A.P. "Multiword lexical units and communicative language teaching". In: ARNAUD, P. and BEJOINT, H. (Eds.). Vocabulary and Applied Linguistics. London, Macmillan, 1992.

Friederici, A. D.; Steinhauer, K. \& Pfeifer, E. "Brain signatures of artificial language processing: Evidence challenging the critical period hypothesis". In: PNAS, vol. 99, 1,2002 , p. 529-534.

FunK, H. et al. Studio D A2: Kurs- und Übungsbuch. Teilband 1. Berlin, Cornelsen, 2006.

GAZZANigA, M. S.; IVRY, R. B. \& MANGUn, G. R. Cognitive neuroscience: the biology of the mind. 2a. ed. New York: Norton, 2002.

González, N. T. M. Cadê o pronome? - O gato comeu. Os pronomes pessoais na aquisiçãolaprendizagem de espanhol por brasileiros adultos. Tese de doutorado. São Paulo, FFLCH-USP, 1994.

Guedes Evangelista, C. R. A modalidade em redações escritas por aprendizes brasileiros de alemão. Tese de doutorado. São Paulo, FFLCH-USP, 2003.

Graf, P., SQuire, L. R., \& MANDler, G. "The information that amnesic patients do not forget". In: Journal of Experimental Psychology: Learning, Memory \& Cognition 10, 1984, 164-178.

Gruber, O. \& GROSCHKE, T. "Executive control emerging from dynamic interactions between brain systems mediating language, working memory and attentional processes". In: Acta Psychologica 115, 2004, 105-121.

HAHNE, A. What's different in second language processing? Evidence from event-related brain potentials, 2001.

HAHNE, A. \& FRIEDERICI, A. D. "Processing a second language: Late learners comprehension mechanisms as revealed by event-related brain potencials". In: Bilingualism: Language and Cognition, 2001.

HAHNE, A., FRIEDERICI, A. D. "Differential task effects on semantic and syntactic processes as revealed by ERPs." In: Cognitive Brain Research, 1998.

KLEIN, W. Zweitspracherwerb. Eine Einführung. Frankfurt/Main: Hain, 1992.

KRASHEN, S. D. The input hypothesis: issues and implications. London: Longman, 1985.

Krashen, S. D. Principles and Practice in Second Language Acquisition. Oxford, Pergamon, 1982.

Krashen, S. D. Second Language Acquisition and Second Language Learning. New York, Pergamon Press, 1981.

KRASHEN, S. D. "El modelo del monitor y la actuación de los adultos en L2". In: LICERAS, J. M. (ed.). La adquisición de las lenguas extranjeras. Madrid, Visor, 1992 (1a. ed. 1977).

Langacker, R. "Cognitive Grammar". In: Geeraerts, D. \& CuYcKens, H (Ed.). The Oxford Handbook of Cognitive Linguistics. Oxford, Oxford University Press, 2007, 421-461. 
Stanich, K.; Meireles, S. - Processamento cognitivo

LARSEN-FreEmAn, D. "Chaos/Complexity Science and Second Language Acquisition”. In: Applied Linguistics 18 (2). Oxford, Oxford University Press ,1997, 141-165.

MCLAUGHLIN, B. "Algunas consideraciones metodologicas sobre el modelo del monitor". In: LICERAS, J. M. (ed.). La adquisición de las lenguas extranjeras. Madrid, Visor, 1992, 153-176 (1a. ed. 1978).

MüLlER, M. et al. Optimal Al (Kursbuch\&Arbeitsbuch). München, Langenscheidt, 2004.

Nattinger, J. R. \& DeCARrico, J. S. Lexical Phrases and language Teaching. Oxford, Oxford University Press, 1992.

Paiva, V. L. M. O. "Modelo fractal de aquisição de línguas”. In: Bruno, F. T. C. (Org.). Ensino-Aprendizagem de Línguas Estrangeiras: Reflexão e Prática. São Paulo, Claraluz, 2005.

PAWley, A. \& Syder, F. H. "Two puzzles for linguistic theory: Native like selection and native like fluency". In: RICHARDS, J. \& SCHMIDT, R. (Eds.) Language and Communication. London, Longman, 1983.

Peters, A. The units of language acquisition. New York, Cambridge University Press, 1983, 131.

ScArPa, E. M. “Aquisição da linguagem". In: Mussalim, F.; Bentes, A.C. Introdução à lingüística: domínios e fronteiras, v.2. São Paulo, Cortez, 2001.

SCHWARZ, M. Einführung in die kognitive Linguistik. Tübingen, Francke, 1992.

Sinclair, J. M. Corpus, Concordance, Collocation. Oxford, Oxford University Press, 1991.

Squire, L. R., Ojemann, J. G., Miezin, F. M., Petersen, S. E., Videen, T. O., \& Raichle, M. E. "Activation of the hippocampus in normal humans: A functional anatomical study of memory". In: Proceedings of the National Academy of Sciences 89, 1992, 1837-1841.

Squire, L. R. \& Zola-Morgans, S. “The medial temporal lobe system”. In: Science 253, 1991, 1380-1386.

SQuire, L. R. \& Zola-Morgans, S. "Memory: brain systems and behavior". In: Trends in Neurosciences 11, 1988, p. 170-175.

Stanich, K. Aspectos do processamento cognitivo relacionado à produção em língua estrangeira e aprendizagem de falantes não-nativos de alemão: hipótese explicativa. São Paulo, FFLCH-USP, 2008 http://www.teses.usp.br/teses/disponiveis/8/8144/tde-27022009-144843/

UlLman, M.T. "A neurocognitive perspective on language: The declarative/procedural model". In: Nature Reviews Neuroscience 2, 2001, 717-726.

UlLman, M.T. et al. "Sex differences in the neurocognition of language". In: Brain and Language 83, 2002, 9-224.

Wray, A. Formulaic Language and the Lexicon. Cambridge, Cambridge University Press, 2002.

XAVIER, G. F. "Memória: correlatos anátomo-funcionais". In: NiTRINI, R., CARAMELLI, P. \& MANSUR, L. (Eds.). Neuropsicologia: das bases anatômicas à reabilitação, 1996, p. 107-129. 